\title{
Differences in Leaf Functional Traits between Simple and Compound Leaves of Canavalia maritime
}

\author{
Bingde Wu, Jun Liu, Kun Jiang, Jiawei Zhou, Congyan Wang* \\ Institute of Environment and Ecology, Academy of Environmental Health and Ecological Security, \\ and School of the Environment and Safety Engineering, Jiangsu University, Zhenjiang, P. R. China
}

Received: 9 January 2018

Accepted: 28 February 2018

\begin{abstract}
The response of leaf functional traits to the shift in environmental variables can raise plant adaptiveness in a wide variety of habitats and subsequently broaden their ecological niche. This study aims to determine the differences in leaf functional traits between simple and compound leaves of Canavalia maritime to illuminate the mechanisms underlying the ecological strategy of plant species with different leaf forms. Single-leaf wet weight of compound leaves of $C$. maritime was significantly lower than that of simple leaves of $C$. maritime. Thus, compound leaves of $C$. maritime possess higher resource capture ability as well as higher relative growth rate than simple leaves of $C$. maritime. The petiole length of compound leaves of $C$. maritime was significantly higher than that of simple leaves of $C$. maritime. Thus, the biomass allocation to petiole for compound leaves of $C$. maritime was significantly higher than that of simple leaves of $C$. maritime. Meanwhile, the higher range of phenotypic plasticity of SLA of compound leaves of C. maritima may enhance the advantage in resource (especially sunlight) capture and use efficiency by shifting the material investment per unit area and per lamina.
\end{abstract}

Keywords: Canavalia maritime, leaf form, leaf functional traits, simple leaf, compound leaf

\section{Introduction}

Leaves can enable plant species absorb sunlight, which is perhaps one of the most critical environmental factors that affect plant growth and survival [1-2]. In particular, leaves often exposed to a multivariate habitat and thereby the response of leaf functional traits to the shift in environmental variables can raise plant adaptiveness in a wide variety of habitats and

*e-mail: liuyuexue623@163.com subsequently broaden their ecological niche [3-7]. As one of the most fundamental leaf functional traits, specific leaf area (SLA) is used as a proxy for the resource-use strategy of plants [3, 8-10]. Specific leaf area is defined as the investment of sunlight capture surface per unit area of leaf [3, 8-10]. Generally, leaves with high SLA values are typically associated with higher resource acquisition and use efficiency, faster growth rates, more rapid turnover of leaf material, and lower investment in leaf construction and protective tissues than leaves with low SLA [3, 8-10]. In addition, petiole length (indicative of the material investment on the support 
of lamina structures), leaf size (indicated by leaf length and leaf width; indicative of leaf photosynthetic area), leaf shape index (calculated as the ratio of leaf length to leaf width; indicative of leaf shape and variation), leaf chlorophyll and nitrogen $(\mathrm{N})$ concentrations (indicative of leaf photosynthetic capacity), and single-leaf wet weight (indicative of the material investment on lamina structures) are also crucial indices of leaf functional traits because those indices are also used as powerful indicators of the resource-use strategy of plants $[3,4-8$, $11-13]$.

Normally, leaf functional traits may vary by leaf forms because leaf forms vary in their biomass allocation strategy and the environmental selection pressures [14]. Accordingly, the differences in the leaf functional traits with different leaf forms can characterize their ecological strategy. Malhado et al. [15] found that trees with compound leaves in Amazonia grow faster than those with simple leaves. Meanwhile, the results of Warman et al. [14] revealed that the leaf $\mathrm{N}$ concentration of compound leaves was higher than that of simple leaves. Consequently, determining the differences in leaf functional trait with different leaf forms is important for illuminating the mechanisms underlying the ecological strategy of plant species with different leaf forms.

This study aims to determine the differences in leaf functional traits between simple and compound leaves of Canavalia maritime to illuminate the mechanisms underlying the ecological strategy of plant species with different leaf forms. C. maritima is an annual herbaceous vine. The leaf form of the first leaves of C. maritime is simple with opposite phyllotaxis and the leaf form of subsequent leaves of $C$. maritime is ternate palmate-compound with alternate phyllotaxis. In this study, leaf functional traits (i.e., petiole length, leaf size, leaf shape index, leaf chlorophyll and nitrogen concentrations, single-leaf wet weight, and SLA) of C. maritime with different leaf form were determined to gain insight into its growth mechanisms.

This study tests the following hypotheses. First, the SLA of compound leaves of $C$. maritime may be higher than that of simple leaves of $C$. maritime because compound leaves often arrange the small leaflets along the rachis to maximize sunlight interception [16]. Second, the biomass allocation to petiole for compound leaves of $C$. maritime may be higher than that of simple leaves of $C$. maritime because petiole mass disproportionally increased with increasing lamina mass and twig mass $[16,17]$.

\section{Materials and Methods}

\section{Experimental Design}

C. maritima was selected as the experimental plant species. Its seeds were bought from a local vegetable market in Zhenjiang, China $\left(32.20^{\circ} \mathrm{N}, 119.53^{\circ} \mathrm{E}\right)$ which has a subtropical humid climate. The annual mean temperature of the area is approximately $15.9^{\circ} \mathrm{C}$, and its monthly mean temperature reaches a maximum of $28^{\circ} \mathrm{C}$ in July and decreases to a minimum of $2.9^{\circ} \mathrm{C}$ in January. The annual precipitation is approximately $1101.4 \mathrm{~mm}$, and monthly mean precipitation reaches a maximum of approximately $205.6 \mathrm{~mm}$ in July and decreases to a minimum of approximately $33.4 \mathrm{~mm}$ in December. The site climate summaries are derived from the local yearbook [18].

Experiments were performed by using the pot cultivation experiment. Nine seeds of $C$. maritime were planted in garden pots that contained humus soil. The diameter of each pot was approximately 12 $\mathrm{cm}$. The samples were incubated at room temperature for approximately one month. Deionized water was supplied according to soil moisture during incubation. Sixteen fully expanded and intact leaf samples both of simple and compound leaves of $C$. maritima were collected randomly to determine the functional traits.

\section{Determining Leaf Functional Traits}

Petiole length was determined by ruler measurement $[4,13,19]$.

Leaf shape index was calculated as the ratio of leaf length to the corresponding leaf width [20, 21]. Leaf length is the maximum value along the midrib, while the width is the maximum value perpendicular to the midrib [21]. Leaf length and leaf width were measured using a ruler [4-6, 12, 13, 19].

The relative chlorophyll and $\mathrm{N}$ concentrations in the leaves were estimated with a hand-held plant nutrient meter (TYS-3N, China). TYS-3N was used to calculate the index in "SPAD units" based on absorbance at 650 $\mathrm{nm}$ and $940 \mathrm{~nm}[5,6,12,13]$.

Single-leaf wet weight was determined using an electronic balance with an accuracy of 0.001 g [4-6].

SLA was computed using the ratio of the leaf area to the corresponding leaf dry weight $\left(\mathrm{cm}^{2} \mathrm{~g}^{-1}\right)$, according to previous studies [4-6, 8].

Plasticity index - the index ranged from zero (no plasticity) to one (maximum plasticity) - of leaf functional traits of both simple and compound leaves of C. maritime were calculated with the following equation $[22,23]$ :

$$
\text { Plasticity index }=\frac{\text { Maximum mean }- \text { minimum mean }}{\text { Maximum mean }}
$$

\section{Statistical Analyses}

Data were verified to determine the deviations from normality and homogeneity of the variances before data analysis using the Shapiro-Wilk normality test. One-way ANOVA was performed to evaluate the differences in leaf functional traits of simple and compound leaves of C. maritime. Correlation analysis was performed using 
Table 1. Differences in leaf functional traits between simple and compound leaves of C. maritime.

\begin{tabular}{|c|c|c|c|c|c|c|c|c|}
\hline Leaf form & PL & LL & LW & LSI & LCC & LNC & SLWW & SLA \\
\hline \multirow{2}{*}{ Simple } & $5.175 \pm$ & $12.000 \pm$ & $13.419 \pm$ & $0.900 \pm$ & $41.138 \pm$ & $3.431 \pm$ & $2.363 \pm$ & $512.604 \pm$ \\
& $0.264 \mathrm{~b}$ & $0.606 \mathrm{~ns}$ & $0.676 \mathrm{a}$ & $0.028 \mathrm{~b}$ & $1.934 \mathrm{~ns}$ & $0.136 \mathrm{~ns}$ & $0.217 \mathrm{a}$ & $23.061 \mathrm{~ns}$ \\
\hline \multirow{2}{*}{ Compound } & $8.344 \pm$ & $13.177 \pm$ & $7.392 \pm$ & $1.794 \pm$ & $43.240 \pm$ & $3.579 \pm$ & $1.084 \pm$ & $508.390 \pm$ \\
& $0.555 \mathrm{a}$ & $0.507 \mathrm{~ns}$ & $0.291 \mathrm{~b}$ & $0.047 \mathrm{a}$ & $1.051 \mathrm{~ns}$ & $0.070 \mathrm{~ns}$ & $0.079 \mathrm{~b}$ & $31.145 \mathrm{~ns}$ \\
\hline
\end{tabular}

Data (mean with standard error) with different letters in a vertical row indicate a significant difference $(P<0.05)$. "ns" means no significant difference $(P>0.05)$. Abbreviations: PL, petiole length $(\mathrm{cm})$; LL, leaf length $(\mathrm{cm})$; LW, leaf width $(\mathrm{cm})$; LSI, leaf shape index; LCC, leaf chlorophyll concentration (SPAD); LNC, leaf nitrogen concentration ( $\left.\mathrm{mg} \mathrm{g}^{-1}\right)$; SLWW, single-leaf wet weight (g); SLA, specific leaf area $\left(\mathrm{cm}^{2} \mathrm{~g}^{-1}\right)$.

the Pearson product-moment correlation coefficient to determine the patterns among various dependent variables. All statistical analyses were performed using IBM SPSS Statistics (version 22.0; IBM Corp., Armonk, NY, USA). Then a Mantel test [24] was performed using
TFPGA (version 1.3) to determine the relationships given in the correlation matrix between leaf functional traits of simple leaves of $C$. maritime and those of compound leaves of $C$. maritime. Statistical significance was set at $P$ values equal to or lower than 0.05 .

Table 2. ANOVA of the effects of leaf form on leaf functional traits of $C$. maritime.

\begin{tabular}{|c|c|c|c|c|c|c|}
\hline & & Sum of Squares & $d f$ & Mean Square & $F$ & $P$ \\
\hline \multirow{3}{*}{ PL } & Between Groups & 80.328 & 1 & 80.328 & 26.596 & $<0.001$ \\
\hline & Within Groups & 90.609 & 30 & 3.020 & & \\
\hline & Total & 170.937 & 31 & & & \\
\hline \multirow{3}{*}{ LL } & Between Groups & 10.928 & 1 & 10.928 & 2.188 & 0.150 \\
\hline & Within Groups & 149.854 & 30 & 4.995 & & \\
\hline & Total & 160.782 & 31 & & & \\
\hline \multirow{3}{*}{ LW } & Between Groups & 291.008 & 1 & 291.008 & 67.155 & $<0.001$ \\
\hline & Within Groups & 130.002 & 30 & 4.333 & & \\
\hline & Total & 421.010 & 31 & & & \\
\hline \multirow{3}{*}{ ISI } & Between Groups & 6.406 & 1 & 6.406 & 264.082 & $<0.001$ \\
\hline & Within Groups & 0.728 & 30 & 0.024 & & \\
\hline & Total & 7.133 & 31 & & & \\
\hline \multirow{3}{*}{ LCC } & Between Groups & 35.490 & 1 & 35.490 & 0.916 & 0.346 \\
\hline & Within Groups & 1162.337 & 30 & 38.745 & & \\
\hline & Total & 1197.827 & 31 & & & \\
\hline \multirow{3}{*}{$\mathrm{LNC}$} & Between Groups & 0.195 & 1 & 0.195 & 1.044 & 0.315 \\
\hline & Within Groups & 5.612 & 30 & 0.187 & & \\
\hline & Total & 5.807 & 31 & & & \\
\hline \multirow{3}{*}{ SLWW } & Between Groups & 13.146 & 1 & 13.146 & 30.830 & $<0.001$ \\
\hline & Within Groups & 12.792 & 30 & 0.426 & & \\
\hline & Total & 25.938 & 31 & & & \\
\hline \multirow{3}{*}{ SLA } & Between Groups & 142.172 & 1 & 142.172 & 0.012 & 0.914 \\
\hline & Within Groups & 360443.509 & 30 & 12014.784 & & \\
\hline & Total & 360585.681 & 31 & & & \\
\hline
\end{tabular}

$P$ values equal to or lower than 0.05 are in bold print. Abbreviations have the same meanings as described in Table 1. 
Table 3. Differences in plasticity indices of leaf functional traits between simple and compound leaves of C. maritime.

\begin{tabular}{|c|c|c|c|c|c|c|c|c|}
\hline Leaf form & PL & LL & LW & LSI & LCC & LNC & SLWW & SLA \\
\hline Simple & 0.577 & 0.565 & 0.429 & 0.436 & 0.448 & 0.405 & 0.808 & 0.416 \\
\hline Compound & 0.496 & 0.371 & 0.446 & 0.395 & 0.281 & 0.242 & 0.640 & 0.553 \\
\hline
\end{tabular}

Abbreviations have the same meanings as described in Table 1.

Table 4. Relationship among leaf functional traits of simple and compound leaves of C. maritime.

\begin{tabular}{|c|c|c|c|c|c|c|c|c|c|c|}
\hline & & & PL & LL & LW & LSI & LCC & LNC & SLWW & SLA \\
\hline \multirow{4}{*}{ PL } & \multirow{2}{*}{ Simple } & $\mathrm{r}$ & 1.000 & $0.812 * * *$ & $0.765^{* * *}$ & 0.081 & 0.160 & 0.149 & $0.734^{* *}$ & $-0.594^{*}$ \\
\hline & & $P$ & & $<0.001$ & $<0.001$ & 0.766 & 0.554 & 0.583 & 0.001 & 0.015 \\
\hline & \multirow{2}{*}{ Compound } & $\mathrm{r}$ & 1.000 & $0.570 *$ & 0.358 & 0.167 & 0.177 & 0.251 & $0.735^{* *}$ & $-0.587 *$ \\
\hline & & $P$ & & 0.021 & 0.173 & 0.536 & 0.511 & 0.349 & 0.001 & 0.017 \\
\hline \multirow{4}{*}{ LL } & \multirow{2}{*}{ Simple } & $\mathrm{r}$ & & 1.000 & $0.853 * * *$ & 0.288 & 0.132 & 0.118 & $0.756 * * *$ & $-0.667 * *$ \\
\hline & & $P$ & & & $<0.001$ & 0.280 & 0.627 & 0.662 & $<0.001$ & 0.005 \\
\hline & \multirow{2}{*}{ Compound } & $\mathrm{r}$ & & 1.000 & $0.711 * *$ & 0.335 & -0.051 & -0.012 & $0.883 * * *$ & -0.070 \\
\hline & & $P$ & & & 0.002 & 0.204 & 0.850 & 0.963 & $<0.001$ & 0.797 \\
\hline \multirow{4}{*}{ LW } & \multirow{2}{*}{ Simple } & $\mathrm{r}$ & & & 1.000 & -0.249 & -0.083 & -0.102 & $0.894 * * *$ & $-0.731 * *$ \\
\hline & & $P$ & & & & 0.353 & 0.760 & 0.706 & $<0.001$ & 0.001 \\
\hline & \multirow{2}{*}{ Compound } & $\mathrm{r}$ & & & 1.000 & -0.412 & 0.015 & 0.026 & $0.745 * * *$ & -0.192 \\
\hline & & $\mathrm{P}$ & & & & 0.113 & 0.955 & 0.924 & $<0.001$ & 0.476 \\
\hline \multirow{4}{*}{ LSI } & \multirow{2}{*}{ Simple } & $\mathrm{r}$ & & & & 1.000 & 0.406 & 0.419 & -0.216 & 0.127 \\
\hline & & $P$ & & & & & 0.119 & 0.106 & 0.421 & 0.640 \\
\hline & \multirow{2}{*}{ Compound } & $\mathrm{r}$ & & & & 1.000 & -0.152 & -0.103 & 0.126 & 0.218 \\
\hline & & $P$ & & & & & 0.574 & 0.704 & 0.643 & 0.418 \\
\hline \multirow{4}{*}{ LCC } & \multirow{2}{*}{ Simple } & $\mathrm{r}$ & & & & & 1.000 & $0.998 * * *$ & -0.218 & 0.014 \\
\hline & & $P$ & & & & & & $<0.001$ & 0.417 & 0.959 \\
\hline & \multirow{2}{*}{ Compound } & $\mathrm{r}$ & & & & & 1.000 & $0.960 * * *$ & 0.095 & $-0.579 \%$ \\
\hline & & $P$ & & & & & & $<0.001$ & 0.727 & 0.019 \\
\hline \multirow{4}{*}{ LNC } & \multirow{2}{*}{ Simple } & $\mathrm{r}$ & & & & & & 1.000 & -0.242 & 0.033 \\
\hline & & $P$ & & & & & & & 0.367 & 0.903 \\
\hline & \multirow{2}{*}{ Compound } & $\mathrm{r}$ & & & & & & 1.000 & 0.185 & $-0.683 * *$ \\
\hline & & $P$ & & & & & & & 0.493 & 0.004 \\
\hline \multirow{4}{*}{ SLWW } & \multirow{2}{*}{ Simple } & $\mathrm{r}$ & & & & & & & 1.000 & $-0.740 * *$ \\
\hline & & $P$ & & & & & & & & 0.001 \\
\hline & \multirow{2}{*}{ Compound } & $\mathrm{r}$ & & & & & & & 1.000 & -0.429 \\
\hline & & $P$ & & & & & & & & 0.098 \\
\hline \multirow{4}{*}{ SLA } & \multirow{2}{*}{ Simple } & $\mathrm{r}$ & & & & & & & & 1.000 \\
\hline & & $P$ & & & & & & & & \\
\hline & \multirow{2}{*}{ Compound } & $\mathrm{r}$ & & & & & & & & 1.000 \\
\hline & & $P$ & & & & & & & & \\
\hline
\end{tabular}

$*, * *$, and $* * *$ indicate significant differences at $0.05,0.01$, and 0.001 probability level, respectively. $P$ values equal to or lower than 0.05 are in bold print. Abbreviations have the same meanings as described in Table 1. 


\section{Results}

Petiole length and leaf shape index of compound leaves of $C$. maritima were significantly higher than those of simple leaves of C. maritima (Tables 1 and 2, $P<0.001)$. By contrast, leaf width and single-leaf wet weight of compound leaves of C. maritima were significantly lower than those of simple leaves of C. maritima (Tables 1 and $2, P<0.001$ ). No significant difference was observed in leaf length, leaf chlorophyll and nitrogen concentrations, and SLA between simple and compound leaves of C. maritima (Tables 1 and 2, $P>0.05$ ).

Plasticity index of SLA of compound leaves of C. maritima was obviously higher than that of simple leaves of C. maritima (Table 3), while plasticity indices of leaf length, leaf chlorophyll, and nitrogen concentrations, and single-leaf wet weight of compound leaves of $C$. maritima were obviously lower than those of simple leaves of C. maritima (Table 3). There was no significant difference in plasticity indices of petiole length, leaf width, and leaf shape index between simple and compound leaves of C. maritima (Table 3).

Many significant correlations were revealed among leaf functional traits for each leaf form of $C$. maritima (Table 4). In particular, petiole length was positively correlated with leaf size and single-leaf wet weight for simple leaves of $C$. maritima (Table $4, P<0.01$ ) and with leaf length and single-leaf wet weight for compound leaves of $C$. maritima (Table 4, $P<0.05$ ). Meanwhile, petiole length was negatively correlated with SLA for both simple and compound leaves of C. maritima (Table 4, $P<0.05$ ). Leaf length was positively correlated with leaf width and single-leaf wet weight for both simple and compound leaves of C. maritima (Table 4, $P<0.01$ ). Meanwhile, leaf length was negatively correlated with SLA for simple leaves of $C$. maritima (Table 4, $P<0.01$ ). Leaf width was positively correlated with single-leaf wet weight for both simple and compound leaves of $C$. maritima (Table 4, $P<0.001$ ). Meanwhile, leaf width was negatively correlated with SLA for simple leaves of C. maritima (Table $4, P<0.01$ ). Leaf chlorophyll concentration was positively correlated with leaf nitrogen concentration for both simple and compound leaves of $C$. maritima (Table 4, $P<0.001$ ). Meanwhile, leaf chlorophyll and nitrogen concentrations were negatively correlated with SLA for compound leaves of C. maritima (Table 4, $P<0.05$ ). Single-leaf wet weight was negatively correlated with SLA for simple leaves of C. maritima (Table 4, $P<0.01$ ).

\section{Discussion}

Plants attempt to develop an optimal and successful ecological strategy of the trade-off between various morphological characteristics to maximize resources and exhibit fitness advantage in the multivariate environments [4, 19]. Generally, compound leaves often arrange the small leaflets along the rachis to maximize sunlight interception [16]. Accordingly, compound leaves may be an important adaptive feature contributing to minimizing branching and to rapid height gain, particularly in sunlight-demanding plant species [16, 25]. Meanwhile, low leaf construction costs are closely related to efficient energy use, which consequently facilitates plant growth [26, 27]. It was therefore expected that compound leaves can display high SLA characterized by high resource acquisition and use efficiency with low leaf construction cost in order to obtain a higher relative growth rate, especially under the condition with overlapping sunlight. However, this study rejected the first hypothesis by showing that no significant difference was observed in SLA between simple and compound leaves of C. maritima. Accordingly, there are no differences in the material investment per unit area and per lamina between simple and compound leaves of $C$. maritime. Hence, SLA may not necessarily contribute to successful ecological strategy of compound leaves of C. maritima in this study. However, single-leaf wet weight of compound leaves of $C$. maritime was significantly lower than that of simple leaves of $C$. maritime. To some extent, this indicated that compound leaves of $C$. maritime possess higher resource capture ability as well as higher relative growth rate than simple leaves of $C$. maritime, suggesting that single-leaf wet weight rather than SLA may play an important role during the process of successful ecological strategy of simple and compound leaves of C. maritime. Meanwhile, the higher leaf shape index and the lower leaf width of compound leaves of $C$. maritime than simple leaves of $C$. maritime can improve the efficiency of resource capture (especially sunlight capture) via adjustments to leaf shape and size [7] for compound leaves of $C$. maritime to maximize reducing the negative effects of overlapping sunlight on leaf growth.

A previous study found that the petiole mass disproportionally increased with increasing lamina mass and twig mass, and the costs of supporting the lamina increased with increasing twig size due to the allometric relationship between petiole mass and twig mass $[4$, 17, 19, 28]. Consequently, the biomass allocation to petiole for compound leaves may be significantly higher than those for simple leaves. The result of this study revealed that the petiole length of compound leaves of C. maritime was significantly higher than that of simple leaves of $C$. maritime. This indicated that the biomass allocation to petiole for compound leaves of $C$. maritime was significantly higher than that of simple leaves of C. maritime. This was consistent with the study's second hypothesis. Previous studies also found that lamina support of plant species with compound leaves was significantly higher than that of plant species with simple leaves [16, 19]. The higher biomass allocation to petiole of compound leaves than simple leaves can contribute to its advantages of lamina support $[16,19]$. 
In particular, leaf petiole exhibited a raised robustness to enable leaves to adapt to the updated pattern of resource allocation [4]. This study also found that petiole length shows a strongly positive correlation with leaf size as well as single-leaf wet weight. Thus to a certain extent, branching is expensive in terms of gaining height for resource capture (especially sunlight capture) [19].

The phenotypic plasticity of leaf functional traits of plant species can enable plants to occupy a wide variety of environmental conditions and then enhance their competitive advantage $[3,22,23,29]$. In particular, the higher range of phenotypic plasticity of plants for any functional traits may play a key role in their successful strategy [3, 22, 23, 29]. This study showed that the plasticity index of SLA of compound leaves of $C$. maritima was obviously higher than that of simple leaves of $C$. maritima. The higher range of phenotypic plasticity of SLA of compound leaves of C. maritima may enhance the advantage in resource (especially sunlight) capture and use efficiency by shifting the material investment per unit area and per lamina.

Generally, leaf size was positively correlated with SLA because leaves with a high SLA payment low biomass into leaf structures and leaves with low SLA allocate more structural investment [3, 9-11]. However, unlike these previous studies, SLA shows a negative correlation with leaf size for simple leaves of $C$. maritime. The negative relationship between SLA and leaf size may be ascribed to that species with larger leaves having diminishing returns on the biomass they invest in sunlight capture and run-away selection for species with smaller leaves [30]. Thus, leaves with larger size did not always invest low resource allocation on leaf construction and possess low SLA [6]. In addition, SLA did not have a significant relationship with leaf size for compound leaves of $C$. maritima in this study. Conflicting results for the correlations between leaf size and SLA also arrived by previous studies, including positive $[6,31]$, negative $[4,30]$, or unrelated $[5,19$, 32]. Accordingly, the relationship between leaf size and SLA varies by species as well as leaf forms. Based on the results of the Mantel test, there were significant positive correlation patterns between leaf functional traits of simple leaves of $C$. maritima and those of compound leaves of $C$. maritima. Hence, the correlation patterns between leaf functional traits of simple leaves of C. maritima and those of compound leaves of C. maritima are similar. Consequently, the main factor affecting the successful ecological strategy of simple and compound leaves of $C$. maritime may be ascribed to the differences in leaf functional traits between simple and compound leaves of $C$. maritime rather than the differences in the correlation patterns among leaf functional traits between simple and compound leaves of C. maritime.

\section{Conclusions}

The purpose of this study was to evaluate differences in leaf functional traits between simple and compound leaves of $C$. maritime to illuminate the mechanisms underlying the ecological strategy of plant species with different leaf forms. No significant difference was observed in SLA between simple and compound leaves of $C$. maritima. However, single-leaf wet weight of compound leaves of $C$. maritime was significantly lower than that of simple leaves of $C$. maritime. Thus, compound leaves of $C$. maritime possess higher resource capture ability as well as higher relative growth rate than simple leaves of $C$. maritime, suggesting that single-leaf wet weight rather than SLA may play an important role during the process of successful ecological strategy of simple and compound leaves of $C$. maritime. The petiole length of compound leaves of $C$. maritime was significantly higher than that of simple leaves of $C$. maritime. Thus, the biomass allocation to petiole for compound leaves of $C$. maritime was significantly higher than that of simple leaves of C. maritime. SLA shows a negative correlation with leaf size for simple leaves of $C$. maritime, while SLA did not have a significant relationship with leaf size for compound leaves of $C$. maritima. Thus, the relationship between leaf size and SLA may vary by leaf forms. The plasticity index of SLA of compound leaves of C. maritima was obviously higher than that of simple leaves of $C$. maritima. The higher range of phenotypic plasticity of SLA of compound leaves of C. maritima may enhance the advantage in resource (especially sunlight) capture and use efficiency by shifting the material investment per unit area and per lamina. Meanwhile, the main factor affecting the successful ecological strategy of simple and compound leaves of $C$. maritime may be ascribed to the differences in leaf functional traits between simple and compound leaves of $C$. maritime rather than the differences in the correlation patterns among leaf functional traits between simple and compound leaves of C. maritime.

\section{Acknowledgements}

This study was supported by the State Key Research Development Program of China (2016YFC0502002), the National Natural Science Foundation of China (31300343), and Jiangsu Collaborative Innovation Center of Technology and Material of Water Treatment. We are grateful to the anonymous reviewer for the insightful and constructive comments that greatly improved this manuscript.

\section{Conflict of Interest}

The authors declare no conflict of interest. 


\section{References}

1. LIU F.D., YANG W.J., WANG Z.S., XU Z., LIU H., ZHANG M., LIU Y.H., AN S.Q., SUN S.C. Plant size effects on the relationships among specific leaf area, leaf nutrient content, and photosynthetic capacity in tropical woody species. Acta Oecol 36, 149, 2010.

2. MENG F.Q., CAO R., YANG D.M., NIKLAS K.J., SUN S. Trade-offs between light interception and leaf water shedding: A comparison of shade- and sun-adapted species in a subtropical rainforest. Oecologia 174, 13, 2014.

3. POORTER H., NIINEMETS Ü., POORTER L., WRIGHT I.J., VILLAR R. Causes and consequences of variation in leaf mass per area (LMA): a meta-analysis. New Phytol 182, 565, 2009.

4. WANG C.Y., LIU J., XIAO H.G., DU D. Response of leaf functional traits of Cerasus yedoensis (Mats.) Yü li to serious insect attack. Pol J Environ Stud 25, 333, 2016.

5. WANG C.Y., XIAO H.G., LIU J., ZHOU J.W., DU D.L. Insights into the effects of simulated nitrogen deposition on leaf functional traits of Rhus typhina. Pol J Environ Stud 25, 1279, 2016

6. WANG C.Y., LIU J., XIAO H.G., ZHOU J.W. Differences in leaf functional traits between Rhus typhina and native species. CLEAN-Soil, Air, Water 44, 1591, 2016.

7. SEVIK H., CETIN M., KAPUCU O., ARICAK B., CANTURK U. Effects of light on morphologic and stomatal characteristics of turkish fir needles (Abies nordmanniana subsp. Bornmulleriana mattf.). Fresen Environ Bull 26, 6579, 2017.

8. SCHEEPENS J.F., FREI E.S., STÖCKLIN J. Genotypic and environmental variation in specific leaf area in a widespread Alpine plant after transplantation to different altitudes. Oecologia 164, 141, 2010.

9. PIETSCH K.A., OGLE K., CORNELISSEN J.H.C., CORNWELL W.K., BÖNISCH G., CRAINE J.M., JACKSON B.G., KATTGE J., PELTZER D.A., PENUELAS J., REICH P.B., WARDLE D.A., WEEDON J.T., WRIGHT I.J, ZANNE A.E., WIRTH C. Global relationship of wood and leaf litter decomposability: the role of functional traits within and across plant organs. Global Ecol Biogeogr 23, 1046, 2014.

10. GALLAGHER R.V., RANDALL R.P., LEISHMAN M.R. Trait differences between naturalized and invasive plant species independent of residence time and phylogeny. Conserv Biol 29, 360, 2015.

11. SOUDZILOVSKAIA N.A., ELUMEEVA T.G., ONIPCHENKO V.G., SHIDAKOV I.I., SALPAGAROVA F.S., KHUBIEV A.B., TEKEEV D.K., CORNELISSEN J.H. Functional traits predict relationship between plant abundance dynamic and long-term climate warming. Proc Natl Acad Sci USA 110, 18180, 2013.

12. WANG C.Y., ZHOU J.W., JIANG K., LIU J. Differences in leaf functional traits and allelopathic effects on seed germination and growth of Lactuca sativa between red and green leaves of Rhus typhina. South Afr J Bot 111, 17, 2017.

13. WANG C.Y., JIANG K., LIU J., ZHOU J.W., WU B.D. Moderate and heavy Solidago canadensis L. invasion are associated with decreased taxonomic diversity but increased functional diversity of plant communities in East China. Ecol Eng 112, 55, 2018.

14. WARMAN L., MOLES A.T., EDWARDS W. Not so simple after all: searching for ecological advantages of compound leaves. Oikos 120, 813, 2011.
15. MALHADO A.C.M., WHITTAKER R.J., MALHI Y., LADLE R.J., TER STEEGE H., PHILLIPS O., ARAGÃO L.E.O.C., BAKER T.R., ARROYO L., ALMEIDA S., HIGUCHI N., KILLEEN T.J., MONTEAGUDO A., PITMAN N.C.A., PRIETO A., SALOMÃO R.P., VÁSQUEZ-MARTÍNEZ R., LAURANCE W.F., RAMÍREZ-ANGULO H. Are compound leaves an adaptation to seasonal drought or to rapid growth? Evidence from the Amazon rain forest. Global Ecol Biogeogr 19, 852, 2010.

16. LI G.Y., YANG D.M., SUN S.C. Allometric relationships between lamina area, lamina mass and petiole mass of 93 temperate woody species vary with leaf habit, leaf form and altitude. Funct Ecol 22, 557, 2008.

17. XIANG S., WU N., SUN S.C. Within-twig biomass allocation in subtropical evergreen broad-leaved species along an altitudinal gradient: allometric scaling analysis. Trees 23, 637, 2009.

18. HANG Z.H., WU H.P. Zhenjiang Yearbook (The first edition). Organized by Zhenjiang Municipal People's Government, Writed by Zhenjiang Local Records Office (Vol. 25). In: Chen J, Liu S (eds). Publishing House of Local Records, Beijing, 27, 2016.

19. WANG C.Y., ZHOU J.W., XIAO H.G., LIU J., WANG L. Variations in leaf functional traits among plant species grouped by growth and leaf types in Zhenjiang, China. J For Res 28, 241, 2017.

20. JEONG N., MOON J.K., KIM H.S., KIM C.G., JEONG S.C. Fine genetic mapping of the genomic region controlling leaflet shape and number of seeds per pod in the soybean. Theor Appl Genet 122, 865, 2011.

21. WANG Z., ZHANG L. Leaf shape alters the coefficients of leaf area estimation models for Saussurea stoliczkai in central Tibet. Photosynthetica 50, 337, 2012.

22. VALLADARES F., BALAGUER L., MARTINEZFERRI E., PEREZ-CORONA E., MANRIQUE E. Plasticity, instability and canalization: Is the phenotypic variation in seedlings of sclerophyll oaks consistent with the environmental unpredictability of Mediterranean ecosystems? New Phytol 156, 457, 2002.

23. LAMARQUE L.J., PORTE A.J., EYMERIC C., LASNIER J.-B., LORTIE C.J., DELZON S. A test for pre-adapted phenotypic plasticity in the invasive tree Acer negundo L.. PLoS One 8, e74239, 2013.

24. MANTEL N. The detection of disease clustering and a generalized regression approach. Cancer Res 27, 209, 1967.

25. POORTER L., BONGERS L., BONGERS F. Architecture of 54 moist-forest tree species: traits, trade-offs, and functional groups. Ecology 87, 1289, 2016.

26. NAGEL J.M., GRIFFIN K.L. Construction cost and invasive potential: comparing Lythrum salcaria (Lythraceae) with co-occurring native species along pond banks. Am J Bot 88, 2252, 2001.

27. HOU Q.Q., CHEN B.M., PENG S.L., CHEN L.Y. Effects of extreme temperature on seedling establishment of nonnative invasive plants. Biol Invasions 16, 2049, 2014.

28. NIINEMETS Ü., SACK L. Structural determinants of leaf light-harvesting capacity and photosynthetic potential. Prog Bot 67, 386, 2006.

29. MCINTYRE P.J., STRAUSS S.Y. Phenotypic and transgenerational plasticity promote local adaptation to sun and shade environments. Ecol Evol 28, 229, 2014.

30. NIKLAS K.J., COBB E.D., NIINEMETS U., REICH P.B., SELLIN A., SHIPLEY B., WRIGHT I.J. "Diminishing returns" in the scaling of functional leaf traits across 
and within species groups. Proc Natl Acad Sci USA 104, 8891, 2007.

31. BURNS K.C., BEAUMONT S.A.M. Scale-dependent trait correlations in a temperate tree community. Austral Ecol 34, 670, 2009.

32. WRIGHT I.J., ACKERLY D.D., BONGERS F., HARMS K.E., IBARRA-MANRIQUEZ G., MARTINEZ-RAMOS
M., MAZER S. J., MULLER-LANDAU H.C., PAZ H., PITMAN N.C.A., POORTER L., SILMAN M.R., VRIESENDORP C.F., WEBB C.O., WESTOBY M., WRIGHT S.J. Relationships among ecologicallyimportant dimensions of plant trait variation in seven neotropical forests. An Bot 99, 1003, 2007 